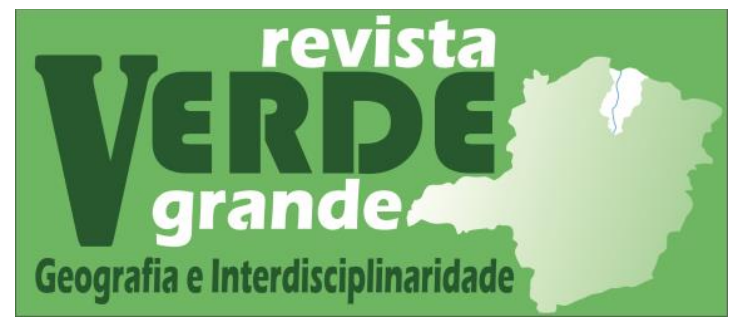

Volume 01, n‥ 02, 2019

https://www.periodicos.unimontes.br/index.php/verdegrande

\title{
DIALOGANDO SOBRE OS ESPAÇOS PÚBLICOS E AS CIDADES NORTE MINEIRAS ${ }^{1}$
}

DIALOGUE ABOUT PUBLIC SPACES AND NORTHERN MINING CITIES

\author{
Carlos Alexandre de Bortolo ${ }^{2}$ https://orcid.org/0000-0003-4304-8824 \\ Christiana de Castro Nogueira Alcântara ${ }^{3}$ https://orcid.org/0000-0002-9539-1176 \\ Ramony Batista ${ }^{4}$ https://orcid.org/0000-0002-8788-3484
}

\begin{abstract}
${ }^{1} \mathrm{O}$ presente estudo e temática foi preliminarmente apresentado em evento científico no ano de 2018 e agora revisado e aprimorado para publicação neste periódico.

${ }^{2}$ Pró-Reitor Adjunto de Pós-Graduação da Universidade Estadual de Montes Claros - UNIMONTES - MG, Professor do Departamento de Geociências e do Programa de Pós-Graduação em Geografia da Unimontes. E-mail: carlos.bortolo@unimontes.br

${ }^{3}$ Bacharelada em Arquitetura e Urbanismo pela Pontifícia Universidade Católica de Minas Gerais - PUC Minas, Professora do curso de Arquitetura e Urbanismo do Centro Universitário FIPMoc - UNIFIPMoc, Metranda do PPGEO - Programa de Pós-Graduação em Geografia da Universidade Estadual de Montes Claros. E-mail: christiana.fipmoc@gmail.com

${ }^{4}$ Licenciada em Geografia pela Unimontes, Mestre pelo PPGEO - Programa de Pós-Graduação em Geografia da Universidade Estadual de Montes Claros, Doutoranda na Pontifícia Universidade Católica de Minas Gerais em Belo Horizonte. E-mail: ramony.batista2712@gmail.com
\end{abstract}

\section{Resumo}

Os espaços públicos estão inseridos nesse contexto de cidade capitalista, como partícipe do jogo de interesses na organização e produção da cidade. Estes espaços possuem grande importância na conjuntura urbana e na sociedade contemporânea, pois constituem espaços de integração, como também, nos apresenta diferentes manifestações no decorrer de sua produção e seus usos. Diante disso, o presente trabalho busca compreender a dinâmica de uso e apropriação destes espaços públicos na cidade média de Montes Claros e a sua importância para valorização do solo urbano; para isso, adotou-se como caminho metodológico a revisão bibliográfica, o mapeamento dos valores de solo urbano, renda e localização destes espaços, posteriormente fez visitas a campo para validação dos dados e registro fotográfico. Por fim, salienta-se que é relevante compreendermos as apropriações e as variadas funções dos espaços públicos, sua acessibilidade, manutenção, seus usos públicos ou com fins privados por determinados agentes produtores da cidade. Assim esses espaços refletem, normalmente, as características sociais e o contexto em que estão inseridos.

Palavras-chave: Cidade, Espaços Públicos, Montes Claros.

\begin{abstract}
Public spaces are inserted in this context of capitalist city, as a participant of the game of interests in the organization and production of the city. These spaces are of great importance in the urban conjuncture and in contemporary society, as they constitute spaces of integration, as well as presenting
\end{abstract}


different manifestations in the course of their production and their uses. Given this, the present work seeks to understand the dynamics of use and appropriation of these public spaces in the average city of Montes Claros and their importance for valuing the urban soil; For this, the bibliographical review, the mapping of urban soil values, income and location of these spaces were adopted as methodological path, and later field visits were made for data validation and photographic record. Finally, it is emphasized that it is relevant to understand the appropriations and the varied functions of public spaces, their accessibility, maintenance, their public or private uses by certain city producing agents. Thus, these spaces usually reflect the social characteristics and the context in which they are inserted.

Keywords: City, Public Spaces, Montes Claros.

\section{Introdução}

A ciência geográfica no período atual tem como desafio pensar não somente o espaço, mas a relação espaço-tempo, tendo em vista que estes são indissociáveis. Deste modo, as relações acontecem em espaço e tempo determinados, a partir disso afirma-se que relações sociais são também espaciais.

Nesta perspectiva, as cidades são entendidas como resultado das características da sociedade que as construíram. Para Corrêa (2001) as cidades são expressões dos processos sociais, econômicos, políticos e culturais vivenciados em um ambiente construído por certo período tempo. Salienta-se que a cidade não é uma formação recente, mas é o capitalismo que oferece as condições para que ocorra uma expansão em escalas maiores. Nessa direção, Carlos (1994) considera que a cidade é primeiramente o que nosso olhar consegue perceber, sendo assim é material e tangível; posteriormente é a cidade das obras e das relações humanas coisificadas e materializadas em espaços distintos de moradia, lazer e consumo.

O espaço citadino é fruto de uma sociedade capitalista e será também contraditório e desigual. As cidades, desde sua concepção são desiguais, porém, é no capitalismo que a desigualdade e contradição passam a estar na base da produção e reprodução dos espaços urbanos, tendo em vista que, essas características estão na essência do capitalismo.

Neste contexto de produção do espaço urbano, os espaços públicos possuem grande importância no contexto das cidades na sociedade contemporânea, pois constituem espaços de integração, como também, nos apresenta diferentes manifestações no decorrer de sua produção e seus usos. Eles possuem função social (à medida que proporcionam encontro e lazer e promovem a socialização dos indivíduos), função organizacional (organizam a infraestrutura da cidade e configuram o desenho urbano), função ecológica (estruturam áreas de proteção ao ambiente) e função cultural (já que fortalecem a identidade local).

Considerando que o espaço público é parte constituinte da história, da política e da vida social nas cidades, nele é possível a interação da sociedade e, consequentemente, 
sua própria estruturação, Leite (2008) afirma que o espaço público constitui espaços de comunicação e ações da cidadania na vida e no cotidiano.

Perante o exposto destaca-se que as transformações vivenciadas pelos diversos espaços urbanos podem também serem observadas nos processos constituintes das cidades norte mineiras. Desta forma, o presente estudo visa compreender as dinâmicas e os usos dos espaços públicos na cidade de Montes Claros. A partir desses elementos, questiona-se: como são produzidos os espaços públicos dessa cidade? Quais são os usos destes espaços?

Diante deste panorama, salienta-se que é relevante compreendermos as apropriações e suas variadas funções dos espaços públicos, sua acessibilidade, manutenção, seus usos públicos e/ou com fins privados por determinados agentes produtores e como o poder público local planeja, executa e organiza a produção dos espaços públicos.

O caminho metodológico adotado para esta pesquisa buscou atender aos questionamentos e objetivos apresentados. Inicialmente fez-se uma revisão bibliográfica, na qual foram priorizadas publicações que abordam a temática em análise como, a produção do espaço urbana, mobilidade, os espaços públicos e privados, e posteriormente sobre os processos urbanos e a dinâmica de usos e apropriações dos espaços públicos no norte de Minas Gerais e na cidade de Montes Claros.

Em um segundo momento, realizou-se a pesquisa documental para compreender como os espaços públicos são abordados na legislação e instrumentos de gestão das cidades; como o Plano Diretor, lei de Uso e Ocupação do solo e Código de posturas e obras de Montes Claros; e o Estatuto das Cidades. Posteriormente, foi feita a coleta de dados no Instituto Brasileiro de Geografia e Estatística - IBGE, acerca das características demográficas e econômicas; e no Atlas de Desenvolvimento Humano, sobre o Índice de Desenvolvimento Humano Municipal e a Renda per capita. Tais dados permitiu uma melhor caracterização da área de estudo.

Após a caracterização dos espaços citadinos adotou-se a divisão intraurbana em áreas de Ponderação, tais áreas são definidas pelo Instituto Brasileiro de Geografia e Estatística IBGE - e entendidas como unidades geográficas constituídas a partir do agrupamento de setores censitários contíguos para a produção de informações acerca dessas áreas. Essas áreas são definidas a partir do número de domicílios permanentes e moradores, sendo que em municípios com população superior a 190 mil habitantes cada área é composta, por no mínimo 400 domicílios.

A cidade de Montes Claros é divida em 22 áreas de ponderação, conforme a figura 01 destaca-se que estas áreas não são homogêneas, apresentando realidades internas contraditórias. 
Figura 01: Mapa de Localização das Áreas de Ponderação em Montes Claros-MG

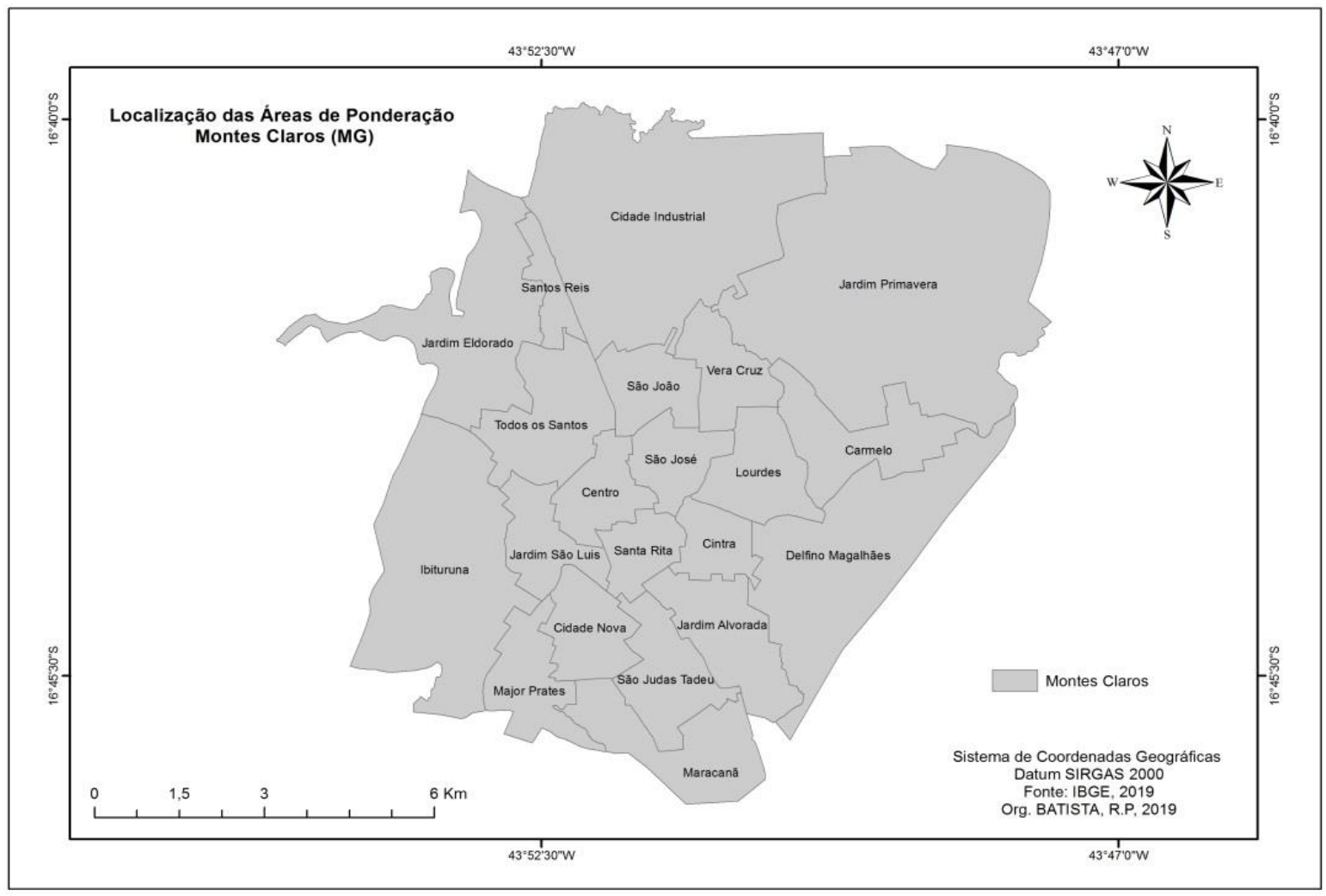

Fonte: IBGE, 2019. Org. Batista, 2019

Em seguida os locais foram pré-definidos a partir das imagens do Google Earth, no qual foi possível identificar os espaços públicos na cidade. Nas visitas aos espaços foram observados os seguintes pontos: 1) qual o uso que a população faz deste espaço?; 2) a qualidade do mobiliário para o uso; 3) a conservação e a presença de vandalismo; 4) a iluminação; 5) a existência de equipamentos para atividade esportiva; 6) arborização; 7) a presença de lixeiras e 8) a presença de serviços públicos como unidades de saúde. Pontua-se que nos ginásios foram observadas também as condições do entorno e a segurança para a prática esportiva; nas praças se o mobiliário existente favorece o uso e a permanência dos citadinos nestas localidades. Foram feitos também os registros fotográficos para melhor compreensão dos possíveis usos e apropriações destes espaços. O presente trabalho apresenta os resultados e as discussões acerca da realidade dos espaços públicos em Montes Claros, as contradições e sua dinâmica de uso e apropriação.

Diante do exposto, considera-se que os espaços públicos na cidade contemporânea também estão subordinados às lógicas do capital e refletem as características socioculturais, ou seja, são impressos em tais espaços as contradições, desigualdades e pluralidades da sociedade que constrói a cidade. Considera-se que, estes espaços desempenham importante 
papel na organização das cidades e no cotidiano dos seus habitantes na medida em que uma parcela de suas atividades é estabelecida nestas áreas. Tais espaços são caracterizados como de lazer, de passagem, de obtenção de renda através do trabalho informal, entre outros.

\section{Breve Caracterização da Área de Estudo}

A porção norte do estado de Minas Gerais apresenta características que a distingue das outras regiões. Para Pereira (2004) o norte é a parte nordestina de Minas, tendo em vista suas características socioeconômicas e culturais. "O conjunto dos fatores edafo-climáticos permite classificar essa região como uma área de transição entre o domínio do cerrado, para o da caatinga. Ocorre, portanto, o predomínio do clima tropical semi-úmido, como incidência de aridez em determinados trechos" (PEREIRA, 2004, p. 15).

É nesta região de características singulares que se localiza o Município de Montes Claros, conforme a figura 02, tendo como municípios limítrofes São João da Ponte, Patis, Mirabela, Coração de Jesus, São João da Lagoa, Engenheiro Navarro, Bocaiúva, Glaucilândia, Juramento, Francisco Sá e Capitão Enéas.

Figura 02: Mapa de Localização do Município de Montes Claros

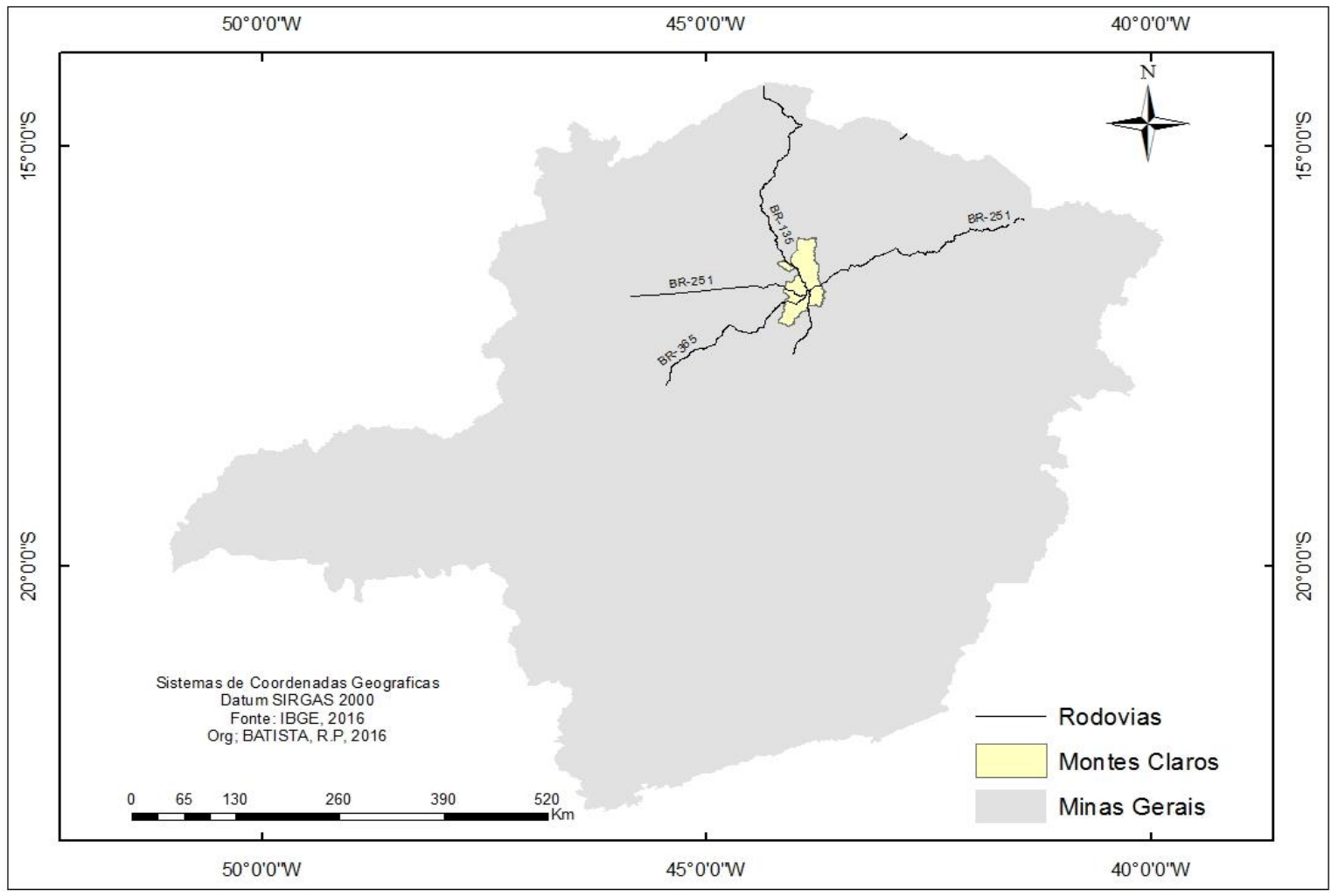

Fonte: IBGE, 2016. Org. BATISTA, 2016. 
O município supracitado ocupa uma área de aproximadamente 3.600, $56 \mathrm{~km}^{2}$ e 404 mil habitantes (IBGE, 2018). Este município se individualiza por ser o principal centro urbano desta região, contribui para isso a sua localização geográfica privilegiada, historicamente, na rota entre as áreas de mineração e criação gado e atualmente, como importante entroncamento rodoviário ligando o nordeste e o sudeste do Brasil, os incentivos do Estado e como dito a singularidade desta região.

O dinamismo econômico pode ser verificado a partir do Produto Interno Bruto - PIB, que é a soma das riquezas produzidas internamente; de acordo como o IBGE (2016), o PIB de Montes Claros soma $\mathrm{R} \$ 8.739 .987,29$. A tabela 01 demonstra a participação dos setores da economia na geração de riquezas.

Tabela 01: Participação dos setores da economia no PIB de Montes Claros - 2016

\begin{tabular}{c|c}
\hline Atividade Econômica & Valor (R\$) \\
\hline Agropecuária & $126.828,73$ \\
\hline Indústria & $1.571 .742,29$ \\
\hline Serviços & $4.522 .804,20$ \\
\hline $\begin{array}{c}\text { Administração, saúde e educação públicas } \\
\text { e Seguridade Social. }\end{array}$ & $1.484 .672,60$ \\
\hline
\end{tabular}

Fonte: IBGE, 2016. Org. BATISTA, 2018.

Como pode ser inferido da tabela, as atividades referentes à indústria e serviços representam, quando somados, a maior parte dos valores que compõem o PIB. Para Batista (2017) a participação da indústria na economia montesclarense foi reduzida, porém, não é insignificante, tendo em vista que representa uma parcela significativa do PIB, observado pela presença de multinacionais e diversificado parque industrial.

Aponta-se que o crescimento econômico, normalmente, não é trazido em melhor divisão de renda e condições igualitárias de vida, tal fato pode ser observado pelo Índice de Desenvolvimento Humano -IDH ${ }^{5}$ - e a renda per capita dos citadinos, conforme a tabela 02.

\footnotetext{
${ }^{5} \mathrm{O}$ Índice de Desenvolvimento Humano é uma medida resumida do progresso ao longo de três anos, tem como base a educação, renda e saúde; é também um contraponto ao PIB per capita, que considera apenas o aspecto econômico do desenvolvimento.
} 
Tabela 02: Montes Claros - Índice de Desenvolvimento Humano por Município e Renda per capita.

\begin{tabular}{c|c|c} 
Ano & IDHM & $\begin{array}{c}\text { Renda } \\
\text { Per capital }\end{array}$ \\
\hline 1991 & 0,515 & 327,75 \\
\hline 2000 & 0,661 & 485,55 \\
\hline 2010 & 0,770 & 650,62
\end{tabular}

Fonte: ATLAS DE DESENVOLVIMENTO HUMANO, 2018. Org. BATISTA, 2018

Os números apresentados na tabela demonstram que o desenvolvimento econômico, nem sempre está atrelado ao desenvolvimento equidade social. Também é possível inferir das informações da tabela que Montes Claros encontra-se em uma zona de médio desenvolvimento humano.

Salienta-se que o dinamismo econômico deste município provoca não somente o crescimento de sua malha urbana, mas também aumento no número de residentes, como poder observado na tabela 03 .

Tabela 03: Evolução da População de Montes Claros no período de 1991 - 2018

\begin{tabular}{c|c|c|c|c|c} 
Ano & $\begin{array}{c}\text { População } \\
\text { Total }\end{array}$ & $\begin{array}{c}\text { População } \\
\text { Urbana }\end{array}$ & $\begin{array}{c}\text { População } \\
\text { Urbana } \\
(\boldsymbol{\%})\end{array}$ & $\begin{array}{c}\text { População } \\
\text { Rural }\end{array}$ & $\begin{array}{c}\text { População } \\
\text { Rural } \\
(\boldsymbol{\%})\end{array}$ \\
\hline 1991 & 250.062 & 227.759 & 91,8 & 22.303 & 8,92 \\
\hline 2000 & 306.947 & 289.947 & 94,21 & 17.764 & 5,7 \\
\hline 2010 & 361.915 & 344.427 & 95,17 & 17.488 & 4,83 \\
\hline 2018 & 404.804 & - & - & - & -
\end{tabular}

Fonte: IBGE, 2018.Org. BATISTA, 2018

É importante pontuar que o final da década de 1960 marca a "passagem da Montes Claros agrária para a Montes Claros Urbano- Industrial” (LEITE, 2004, p. 35). O crescimento econômico deste município não pode ser compreendido à margem da conjuntura econômica e político-social do Brasil (LEITE, 2004).

A inserção do norte de Minas na área de atuação da Superintendência de Desenvolvimento do Nordeste - SUDENE-, promoveu investimentos na industrialização com a criação do Distrito Industrial e atração de novas indústrias. De acordo com Leite (2004, p. 36) "[...] Montes Claros foi a que atraiu mais investimentos, em virtude da localização geográfica, da posição de centro regional e do fato de possuir boa infra-estrutura urbana".

A presença da indústria, a criação de mais postos de trabalhos atrelados ao contexto do campo, como a mecanização da produção e a secas periódicas, favoreceram a migração rural urbana e urbano-urbana. Tal fato gerou mudanças significativas na organização do espaço 
urbano de Montes Claros. As transformações ocorridas neste espaço ratificam a condição de cidade-mercadoria, tendo em vista o surgimento de áreas residenciais diferenciadas, materializando processos como a segregação socioespacial ${ }^{6}$.

Deste modo, considera-se que o acesso a essas áreas com melhor infraestrutura são acessíveis mediante a renda de cada indivíduo, assim, a cidade torna-se uma mercadoria, na qual, o acesso ocorre sob a égide do capital. Montes Claros, não está à margem desses processos, mas os reproduz salvaguardando suas singularidades.

\section{Os espaços Públicos na Cidade de Montes Claros e o Norte Mineiro}

A cidade é entendida como construção coletiva, sendo possível observar em sua paisagem a materialização das características da sociedade que a construiu, sendo, deste modo, o resultado e o reflexo das cidades que a antecederam, é assim, uma construção social e temporal. Carlos (2007) afirma que a cidade é um acumulado de cidades que existiram, ou seja, o que vemos na contemporaneidade é fruto de processo e da ação dos agentes construtores do espaço urbano.

Destaca-se que a cidade capitalista é também a cidade do cotidiano, do simbólico, do vivido e da reprodução da vida. Para Carlos (2007) pensar a cidade sob a perspectiva do cotidiano, não significa negligenciar a ação do capital, mas entender que ele permeia as relações sociais e de produção.

Salienta-se que tal diferenciação não se restringe apenas a moradia, mas inserem nesse contexto de desigualdade e privilégios as demais esferas da vida humana. É nesta cidade, campo de lutas e jogos de interesses que se encontra o indivíduo com seu cotidiano e necessidades para a reprodução da vida. Para Carlos (2014) e neste contexto que os espaços públicos precisam ser pensados e apropriados.

Os espaços públicos, de acordo com Bortolo; Batista e Ribeiro (2018) devem ser entendidos em toda sua amplitude e magnitude, não apenas na visão antagônica ao privado, e que as transformações sociais interferem nas conceituações e conteúdo do público e do privado. "No contexto do capitalismo, o espaço público é pensado pelo viés do consumo e do lucro, sendo assim, passam a serem elementos de segregação e exclusão social” (BORTOLO; BATISTA; RIBEIRO, 2018, s/p).

A partir do exposto, ratifica-se a importância dos espaços públicos na construção e dinâmica da cidade. Sendo que o espaço público urbano é o lócus da socialização e do

\footnotetext{
${ }^{6}$ Sobre a Segregação socioespacial em Montes Claros, vide: Leite (2006), Leite e Pereira (2004) e Batista (2017).
} 
encontro, tendo como papel secundário a construção e apropriação, a articulação e ordenamento territorial e dos diversos usos do espaço urbano. Outro aspecto a ser considerado é que a implantação de espaços públicos nas cidades melhora a qualidade de vida e promovem a arborização e o uso de espaços abandonados (PÉREZ, 2004).

Acerca do conceito de espaço público, Pérez (2004) diz que há diversas definições e adequações ao contexto urbano e seu desenvolvimento.

“[...] la definición y tratamiento de sus espacios públicos, los cuales se han conformado a través de la historia por diversos factores endógenos e exógenos que han caracterizado el proceso de formación y desarrollo urbano y su relación con los elementos constitutivos de lo que formal y normativamente se ha definido como espacio público" (PÉREZ, 2004, p. 28).

Deste modo, as características de forma e conteúdo do espaço público refletem as singularidades de cada contexto urbano. Como dito anteriormente Montes Claros não ficou a margem desse cenário, sendo observadas em seu espaço interno as características de uma cidade mercadoria. Os espaços públicos urbanos apresentam quase sempre um “mix” de usos e formas de apropriações, que como apresentado é permeado pelo capital.

Considera-se então que o espaço da cidade é produção social e coletiva, porém, a apropriação e o acesso às urbanidades são mediados pela renda de cada citadino, essa dinâmica é observada também para os espaços públicos. Para Bortolo (2015), os espaços públicos nas cidades atuais permanecem como ponto de diferenciação nas cidades, porém, na atualidade são também responsáveis pela valorização do solo e o status refere-se ao uso de espaços de lazer privados, como os shoppings Centers.

A produção do espaço não deve ser somente entendida pela maneira como as pessoas requerem e têm acesso a determinados equipamentos e serviços públicos, mas por uma gama de fatores e agentes que acabam por se materializar ou se ocultar na paisagem urbana. Fez-se uma leitura das dinâmicas socioespaciais de produção, apropriação e os usos dos espaços públicos em tela (BORTOLO, 2015, p.6).

Desta maneira, os espaços públicos não são distribuídos aleatoriamente pelo espaço citadino, mas em conformidade com os interesses dos diversos agentes urbanos. A figura 03 demonstra a localização e quais espaços foram visitados durante a pesquisa. 
Figura 03: Localização dos Espaços Públicos visitados em Montes Claros (MG)

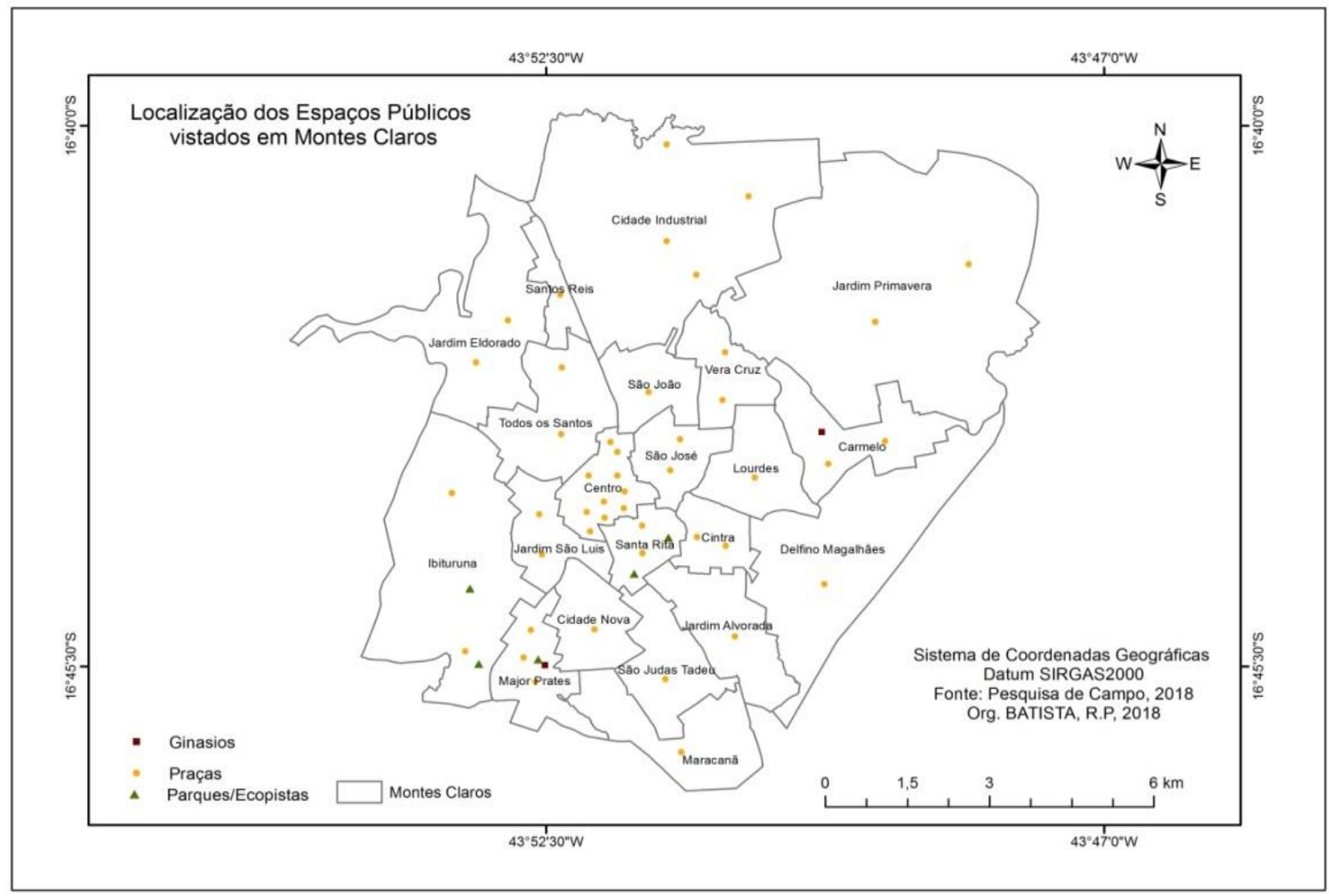

Fonte: Pesquisa de campo, 2018. Org. BATISTA, 2018

A partir do mapa observa-se que os espaços públicos não encontram-se distribuídos de modo igualitário e/ou homogêneo pelas localidades urbanas. Considera-se que a compreensão da escolha locacional destes equipamentos passa pela distribuição da renda dos indivíduos que residem em cada área de ponderação, na qual os citadinos com maior renda ocupam as áreas com maior valor de solo (BATISTA, 2017). A espacialização da renda (figura 04) deixa evidente que a concentração de renda, na cidade em tela é regionalizada, deste modo, a diferença socioespaciais torna-se ainda mais claras. 
Figura 04: Renda Mensal Média por Área de Ponderação em Montes Claros

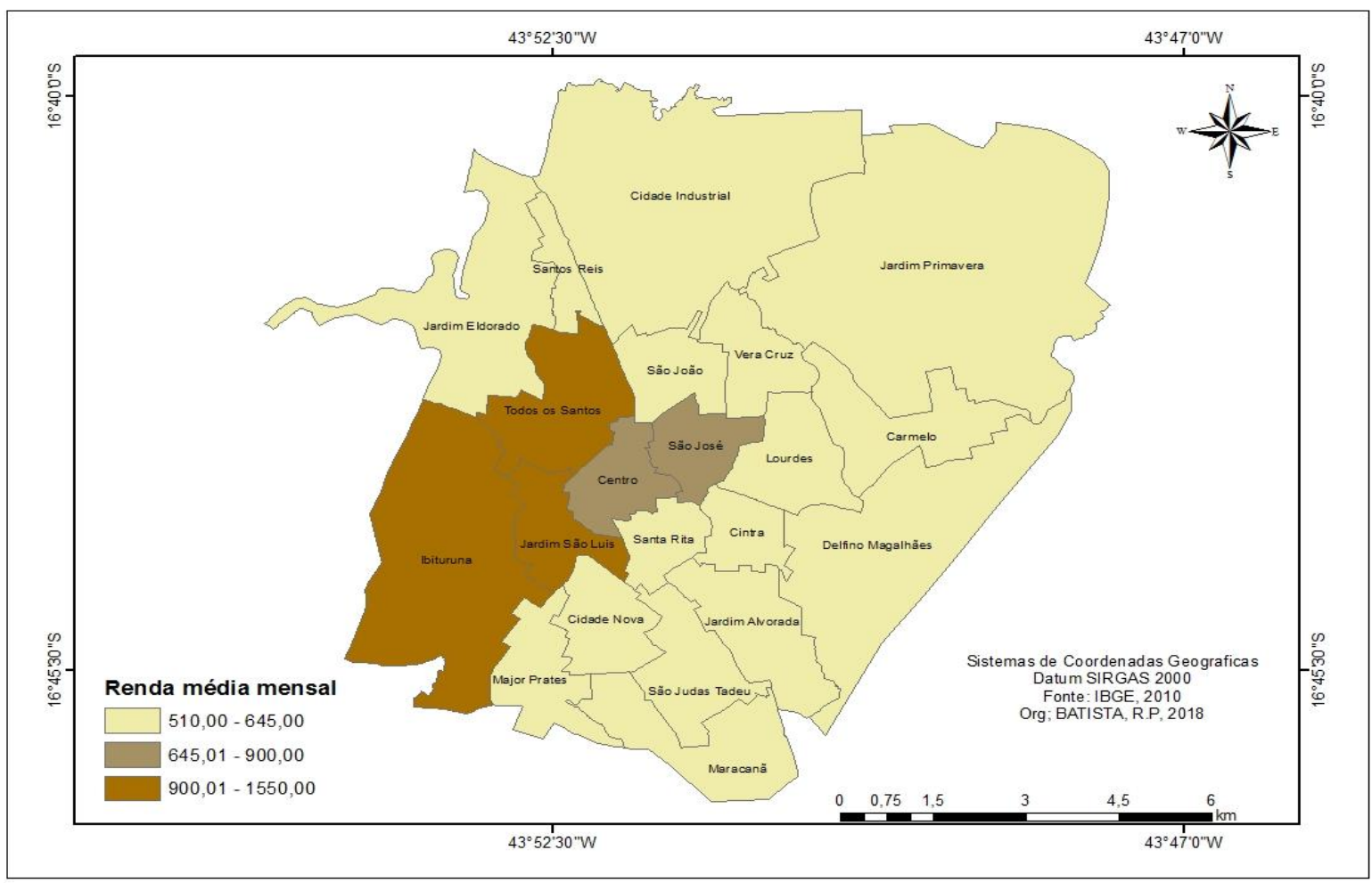

Fonte: IBGE, 2010. Org. BATISTA, 2018

Considera-se que a compreensão da dinâmica dos espaços públicos em Montes Claros está atrelada a renda e valor do solo urbano, assim, infere-se dos mapas que as áreas com maior valor de solo são aquelas com mais equipamentos e residentes de alta renda. A área de Ponderação - Cidade Industrial localiza-se na porção norte da cidade e tendo a maioria dos residentes com renda média mensal entre $\mathrm{R} \$ 510,00$ e 550,00; foram visitados quatro praças, cuja implantação e manutenção é feita pela município. Desta forma, ratifica-se a importância da praça para vida cotidiano e social, além de ser entendida como síntese da organização social e espacial dos contextos em que são inseridas, como pode ser observado na figura 05 . 
Figura 05 e 06: Praça na Área de Ponderação Cidade Industrial - Montes Claros
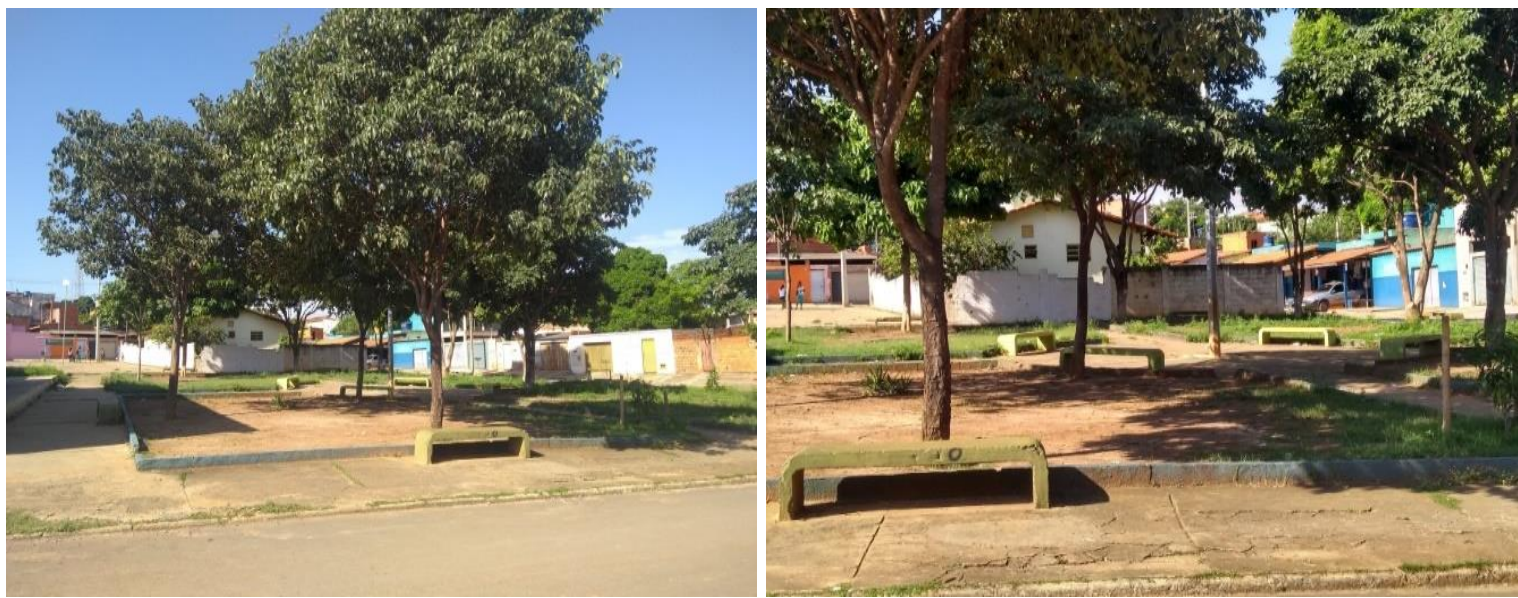

Fonte: BATISTA, 2018.

As praças localizadas nesta área de ponderação encontram-se bem arborizadas, apesar da ausência de cuidados com a jardinagem e são bem iluminadas. Pontua-se que a falta de cuidado com ambiente da praça e demais equipamentos fazem com que a população não crie vínculo com esse espaço e permaneça menos tempo na praça. As praças ainda abrigam Igrejas Católicas que fazem uso deste espaço para celebrações campais e festas de padroeiros e unidades básicas de saúde.

O Jardim Eldorado limita-se com a Área de Ponderação do Ibituruna, que conforme a figura 04 é destinada os moradores de alta renda, ratificando que os conflitos que outrora se dava entre o centro (rico) e a periferia (pobre), agora ocorrem entre áreas periféricas. As Praças visitadas nesta área são usadas pela comunidade, muitas vezes ligadas a atividades esportivas e religiosas (figura 06).

Figura 07: Praças na Área de Ponderação - Jardim Eldorado
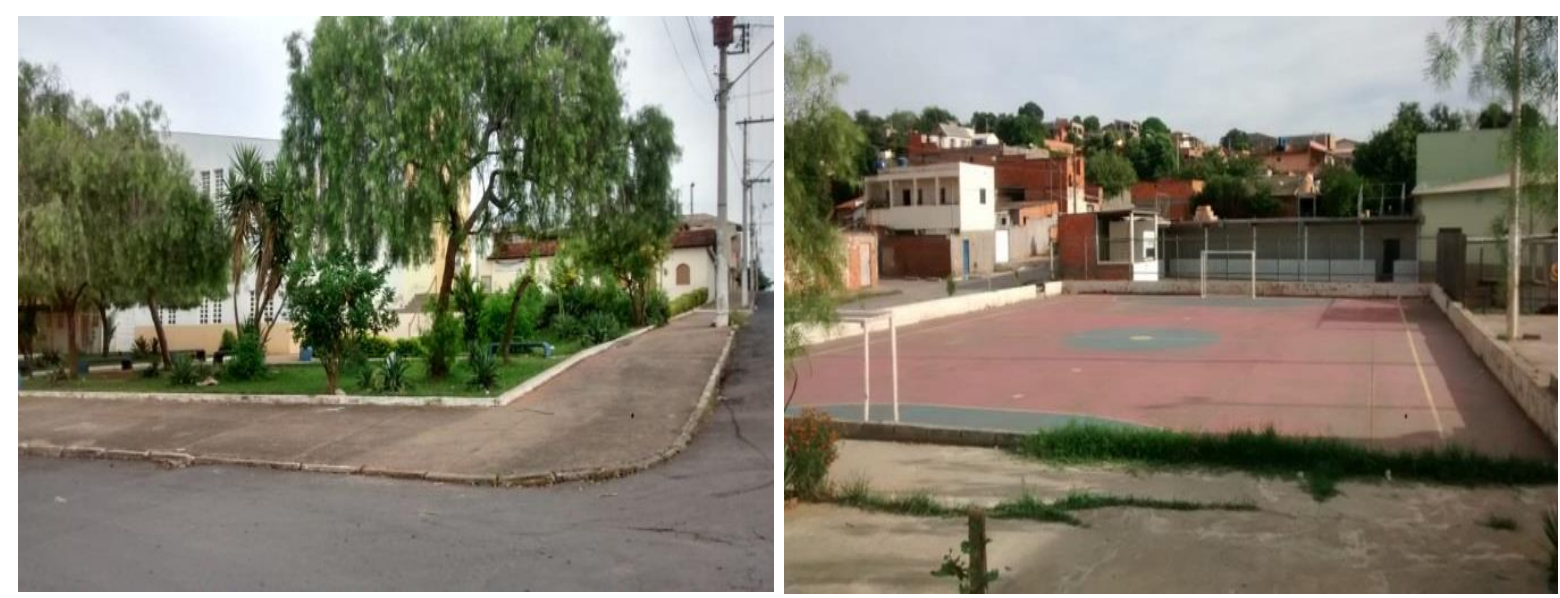

Fonte: BATISTA, 2018.

As praças possuem mobília, como bancos e mesas, bem cuidados, arborização, lixeiras, são bem arborizadas e iluminadas o que favorecem a permanência e o uso do espaço. 
Desta forma, concorda-se com Silva; Silva e Lopes (2009, p. 65), que "o mobiliário urbano em espaços públicos passou a ser introduzido em resposta às necessidades sociais urbanas e técnicas, com isso, as praças passaram a ter um destaque na socialização urbana, devido ao seu mobiliário e equipamentos urbanos".

A Área de Ponderação Ibituruna, como pode ser inferido dos mapas, é ocupado por moradores com alto poder aquisitivo e de acordo com Batista (2017) é uma das áreas com maior valor de solo urbano, sendo escolhida pelo mercado imobiliário como área para implantação dos Espaços Residenciais Fechados de alto luxo. Salienta-se que a valorização desta área também está ligada a atrativos ambientais como a Serra do Mel e aos parques urbanos que favorece maior conforto térmico.

O Parque Sapucaia localizado nesta Área de Ponderação durante a pesquisa esteve fechado para reforma e melhorias dos equipamentos internos. O parque Sagarana (figura 07) revitalizado no ano de 2018, além de ser uma área de preservação é usado pela população para práticas esportivas.

Figura 08: Parque Municipal Sagarana - Área de Ponderação do Ibituruna
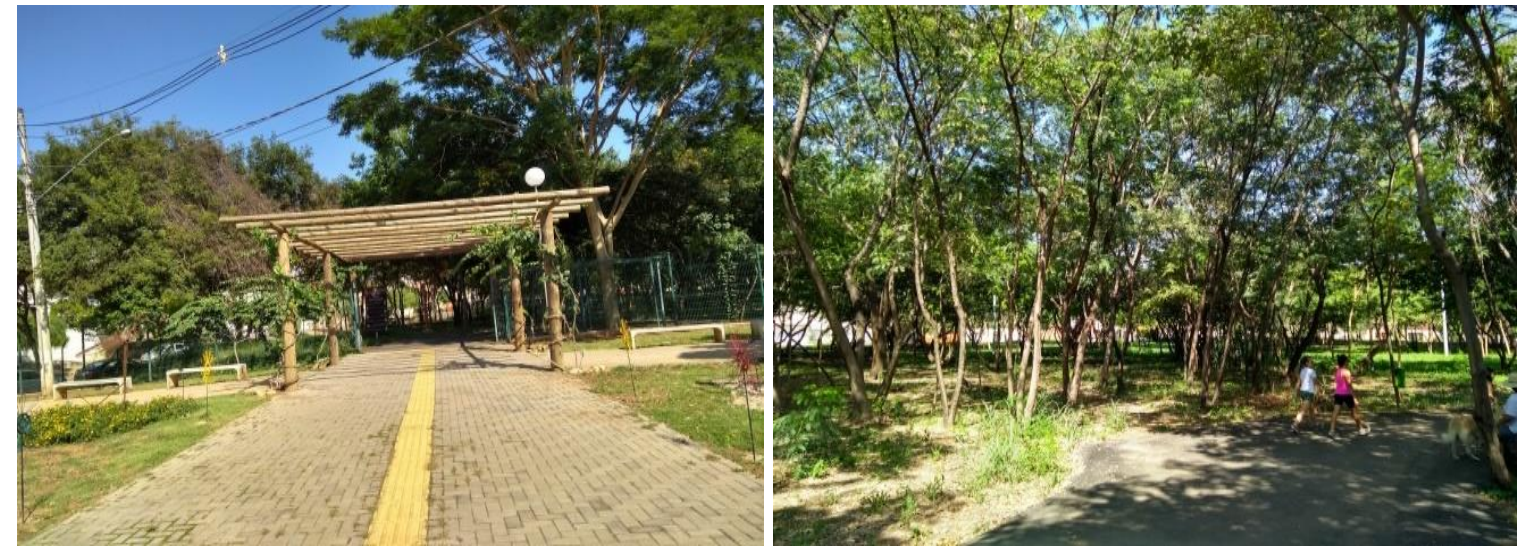

Fonte: BATISTA, 2018.

A Área de Ponderação do Major Prates, de acordo com França (2006) é entendida como um subcentro, deste modo, apresenta uma dinâmica peculiar que a singulariza em relação às demais áreas de ponderação. Nesta área encontra-se além das praças, o Parque Municipal Milton Prates e do Zoológico Municipal (que atualmente está desativado). De acordo com a figura 08 as praças encontram-se bem arborizadas, iluminadas, com mobiliário bem conservado possibilitando um mix de usos tanto para esportes quanto para atividades culturais e religiosas. Estes espaços ainda abrigam unidades de saúde e policiais. 
Figura 09: Praça na Área de Ponderação Major Prates
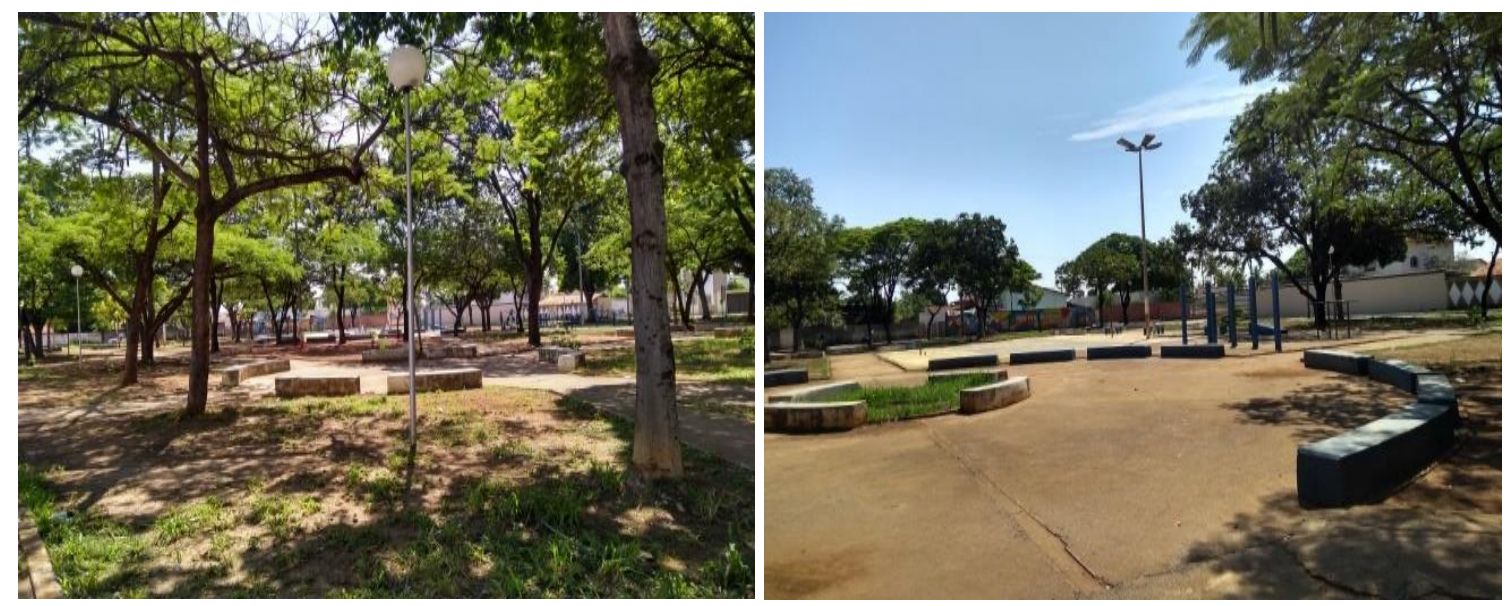

Fonte: BATISTA, 2018.

O Parque Municipal Milton Prates (figura 09), implantado no ano de 1969 pela Prefeitura Municipal de Montes Claros, possui aproximadamente 200 mil metros quadrados, abriga uma lagoa, árvores de variadas espécies, pequenos mamíferos, aves e peixes, uma academia ao ar livre, restaurantes, banheiros, pista para caminhada e um Ginásio Poliesportivo Ana Lopes.

Figura 10: Parque Municipal Milton Prates - Área de Ponderação Major Prates
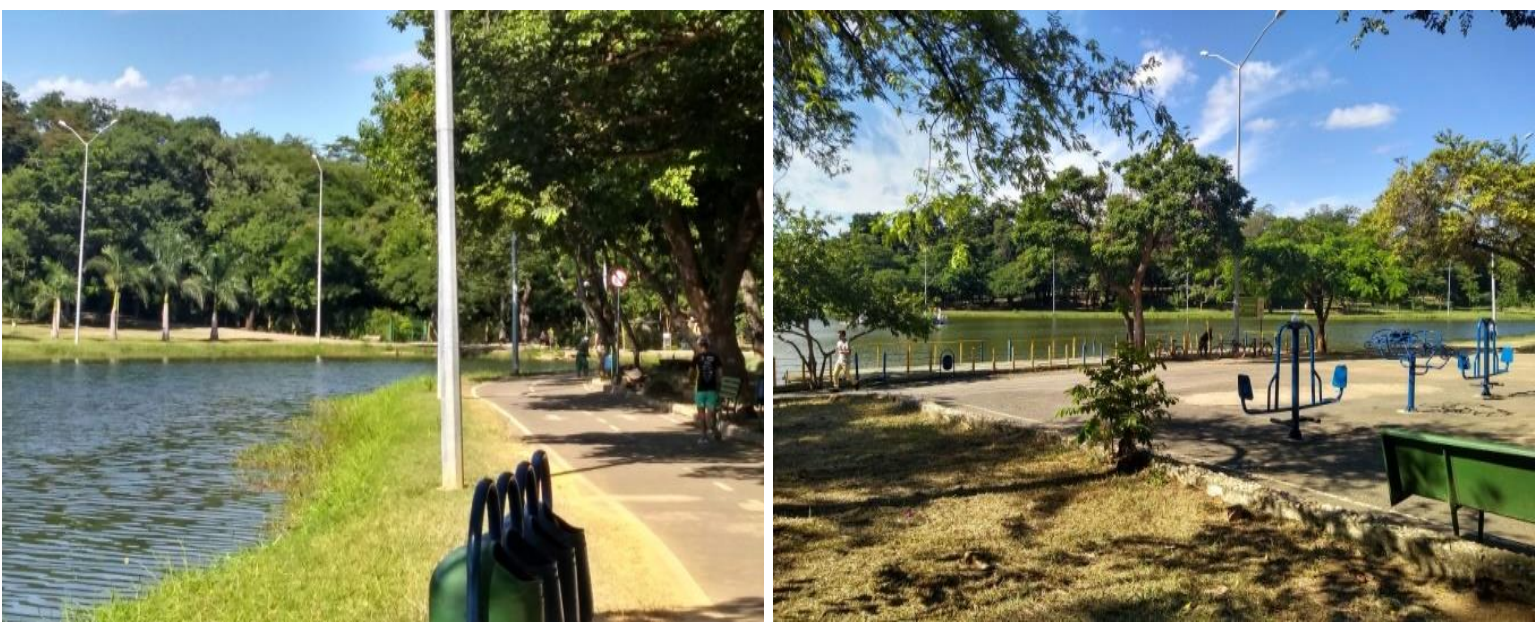

Fonte: BATISTA, 2018.

A partir do panorama apresentado pelas Áreas de Ponderação do Major Prates e Ibituruna que a presença dos parques, praças são fontes de valorização imobiliária, quando não tornam uma área valorizada, aumenta e/ou ratifica a valorização. A partir da breve exposição acerca dos espaços públicos na cidade de Montes Claros, considera-se que o acesso à cidade e suas urbanidades são mediados pela renda de cada indivíduo. 


\section{Considerações Finais}

As cidades são entendidas nesse trabalho como resultado e reflexo da sociedade que cotidianamente a constrói, materializando em sua paisagem e organização espacial as suas características. A cidade no contexto capitalista é simultaneamente campo de lutas e de reprodução do capital, mas também da vida cotidiana, das relações e encontros. Assim, uma sociedade capitalista produz uma cidade com as mesmas contradições e desigualdades, observadas também nas condições de uso e localização dos espaços públicos.

Os espaços públicos inseridos dentro da cidade como lócus do encontro entre os diferentes grupos urbanos e devem ser analisados para além da dicotomia públicos e privados. A compreensão do espaço público na cidade atual passa pela apreensão da sua característica de "possibilitador de encontros impessoais e anônimos e de co-presença dos diferentes grupos sociais" que favorecem com que as pessoas compartilhem o mesmo território, sem, contudo, terem necessidade de se conhecer profundamente" (SOBARZO MINO, 2006, p. 94). Este autor assume a existência da diferença no espaço público, porém não idealiza a existência de uma relação profunda no convívio da diversidade, mas acredita no convívio civilizado, porém impessoal.

Os espaços públicos na cidade de Montes Claros são também inseridos na ótica do encontro e do capital, sendo, normalmente apropriados pelo mercado imobiliário como mecanismo de valorização do solo urbano. Deste modo, pontua-se que o acesso a estes espaços bem como as melhores condições relacionam-se com a renda dos indivíduos residentes nestas localidades.

Considera-se que as praças e parques em áreas com maior valor de solo urbano e, consequentemente ocupadas por pessoas com maior renda, conforme o mapa apresentado, em contrapartida aqueles com menor renda possuem espaços públicos com condições diferentes de uso. Por fim, ratifica-se que a organização espacial da cidade e os espaços públicos estão inseridos na dinâmica de reprodução e acumulação do capital.

\section{REFERÊNCIAS}

Atlas de Desenvolvimento Humano, 2018.

BATISTA, R. P. Segregação Socioespacial e Paisagem Urbana: um estudo da cidade de Montes Claros (MG). Dissertação de Mestrado. Universidade Estadual de Montes Claros Programa de Pós- Graduação em Geografia, Montes Claros (MG), 2017. 
Dialogando sobre os espaços públicos e as cidades Norte Mineiras

Carlos Alexandre de Bortolo

BORTOLO, C.A de; BATISTA, R.P; RIBEIRO, B.S. Espaços públicos e paisagem urbana: breves apontamentos sobre uso e apropriações das praças. Universidade Estadual de Montes Claros - UNIMONTES, Montes Claros, 2018.

BORTOlO, C. A. de. A Dinâmica dos Espaços Públicos de Lazer em Cidades da Aglomeração Urbana de Londrina - PR. Tese de Doutorado em Geografia. Pós-Graduação em Geografia, Universidade Estadual de Maringá. 2015.

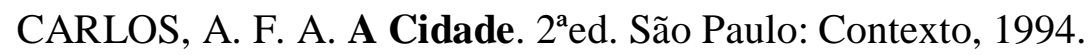

CARLOS, A. F. A. O Espaço Urbano: novos escritos sobre a cidade. FFLCH, São Paulo, 2007.

CORREAA, R. L. Trajetórias Geográficas, $2^{\circ}$ ed. Rio de Janeiro: Bertrand Brasil, 2001.

IBGE, Instituto Brasileiro de Geografia e Estatística, 20018.

LEITE, M. E; PEREIRA, A. M. Metamorfose do Espaço Intra-urbano de Montes Claros. Montes Claros, Unimontes, 2008.

LEITE, Marcos Esdras. Geoprocessamento aplicado ao estudo do espaço urbano: o caso da cidade de Montes Claros - Minas Gerais. 2006. P.177. Dissertação de mestrado em geografia área de concentração em geografia e gestão do território. Instituto de Geografia, Uberlândia, 2006.

LEITE, R. P. Localizando o espaço público: Centrification e cultura urbana. Revista Crítica de Ciências Sociais, $n^{o}$ 83. Dezembro, 2008. pp 35-54

LEITE, M.E e PEREIRA. A. M. A expansão urbana de Montes Claros a partir do processo de industrialização. In. PEREIRA, A. M. e ALMEIDA, M. I. S de (org). Leituras Geográficas sobre o Norte de Minas Gerais. Montes Claros: Unimontes, 2004. P. 33 - 51.

PEREIRA, A. M. A urbanização no sertão norte - mineiro: Algumas Reflexões. IN PEREIRA, A. M e ALMEIDA, M. I.S de (org.). Leituras Geográficas sobre o Norte de Minas Gerais. Montes Claros: Unimontes, 2004. P. 130.

PÉREZ, E. H. Percepción del espacio público. Revista Bitacora, urbano/territorial. $N^{\circ} 8$, 2004. p. 27-31.

SILVA, G. C; LOPES, W. G. R; LOPES, J. B. Aspectos relacionados ao uso e apropriação das praças em áreas centrais de cidades: transformações e permanências. R. RAEGA UFPF. Curitiba, 2009. p 59-78.

MIÑO SOBARZO, O. A. Os Espaços da Sociabilidade Segmentada: a produção do espaço público em Presidente Prudente. Tese de doutorado em Geografia. Universidade Estadual Paulista/ Faculdade de Ciências e Tecnologia. Presidente Prudente (SP): 2005. 